\title{
The relative importance of the Factors II, VII, IX and X for the Prothrombinase activity in plasma of orally anticoagulated patients
}

Citation for published version (APA):

Xi, M., Beguin, S., \& Hemker, H. C. (1989). The relative importance of the Factors II,VII, IX and X for the Prothrombinase activity in plasma of orally anticoagulated patients. Thrombosis and Haemostasis, 62(2), 788-791. https://doi.org/10.1055/s-0038-1646904

Document status and date:

Published: 01/01/1989

DOI:

10.1055/s-0038-1646904

Document Version:

Publisher's PDF, also known as Version of record

Please check the document version of this publication:

- A submitted manuscript is the version of the article upon submission and before peer-review. There can be important differences between the submitted version and the official published version of record.

People interested in the research are advised to contact the author for the final version of the publication, or visit the DOI to the publisher's website.

- The final author version and the galley proof are versions of the publication after peer review.

- The final published version features the final layout of the paper including the volume, issue and page numbers.

Link to publication

\footnotetext{
General rights rights.

- You may freely distribute the URL identifying the publication in the public portal. please follow below link for the End User Agreement:

www.umlib.nl/taverne-license

Take down policy

If you believe that this document breaches copyright please contact us at:

repository@maastrichtuniversity.nl

providing details and we will investigate your claim.
}

Copyright and moral rights for the publications made accessible in the public portal are retained by the authors and/or other copyright owners and it is a condition of accessing publications that users recognise and abide by the legal requirements associated with these

- Users may download and print one copy of any publication from the public portal for the purpose of private study or research.

- You may not further distribute the material or use it for any profit-making activity or commercial gain

If the publication is distributed under the terms of Article $25 \mathrm{fa}$ of the Dutch Copyright Act, indicated by the "Taverne" license above, 


\title{
The Relative Importance of the Factors II, VII, IX and X for the Prothrombinase Activity in Plasma of Orally Anticoagulated Patients
}

\author{
Ma Xi*, S. Béguin, and H. C. Hemker \\ From the Department of Biochemistry, Biomedical Centre, University of Limburg, Maastricht, \\ The Netherlands, and the Haematologic Institute of Xian*, Peoples Republic of China
}

\section{Key words}

Anticoagulant treatment - Prothrombin - Prothrombinase Vitamin $\mathrm{K}$ antagonists

\section{Summary}

The individual importance of each of the four vitamin Kdependent clotting factors on the generation of prothrombinase activity in the plasma of orally anticoagulated patients has been investigated.

Addition of purified factors VII, IX or X to plasma from deeply anticoagulated patients (International Normalized Ratio 2.8-4.8) did not influence the amount of prothrombinase activity or the amount of thrombin formed. Only the prothrombin level in the plasma determines the course of thrombin generation. Addition of increasing amounts of purified factor II, VII, IX or X to plasmas deficient in respectively factor II, VII, IX or X showed that the prothrombinase activity increases linearily with the concentration of factor II added and that the concentration below which the factors VII, IX and X start to have a measurable effect on prothrombinase activity are $5 \%, 20 \%$ and $30 \%$, respectively. Half maximal prothrombinase activity was found at about $1 \%$ factor VII, 5\% factor IX and $8 \%$ factor $X$ respectively.

From these observations we conclude that primarily the variation in factor II level determines thrombin generation and hence presumably the antithrombotic effect of oral anticoagulant therapy. It therefore seems likely that, for the control of oral anticoagulant therapy, tests that reflect factor II activity would be suitable.

\section{Introduction}

The vitamin $\mathrm{K}$-dependent coagulation proteins i.e. prothrombin and factors VII, IX and $\mathrm{X}$, are synthesized in the hepatic parenchymal cells and have the common characteristic of the occurrence of $\gamma$-carboxylated glutamic acid residues in the $\mathrm{N}$ terminal region of the protein chain. The carboxylated coagulation proteins are capable of binding to negatively charged phospholipid surfaces via $\mathrm{Ca}^{2+}$-bridges, this interaction is essential for their effective participation in the coagulation process (1).

Oral anticoagulation by coumarin congeners, interferes with vitamin $\mathrm{K}$-dependent carboxylation. This results in the synthesis of immunologically detectable forms that are biologically inactive or even inhibitory $(2,3)$. The formation of three multicomponent enzymatic complexes of the coagulation cascade, i. e. the extrinsic factor $\mathrm{X}$ activator (thromboplastin and factor $\mathrm{VII}_{\mathrm{a}}$ ) the intrinsic factor $\mathrm{X}$ activator $\left(\mathrm{FIX}_{\mathrm{a}}-\mathrm{FVIII}_{\mathrm{a}}-\mathrm{PL}\right.$ ) and prothrombin converting activity (prothrombinase, $\mathrm{FX}_{\mathrm{a}}-\mathrm{FV}_{\mathrm{a}}-\mathrm{PL}$ ) will be diminished by oral anticoagulant therapy. This, as well as the decrease of

Correspondence to: Dr. H. C. Hemker, University of Limburg, Dept. of Biochemistry, P.O. Box 616, $6200 \mathrm{MD}$ Maastricht, The Netherlands prothrombin may contribute to the diminution of thrombin generation observed in blood from anticoagulated patients.

The effect of coumarin therapy is not immediate. The preexistant circulating clotting factors have to disappear before the level of clotting factors adapts to the new diminished level of synthesis. The various factors decline with velocities dependent upon their half-life times which are approximately: factor VII: 6 hours, factor IX: 14 hours, factor X: 45 hours, factor II: 60 hours (4). Shortly after the beginning of anticoagulant therapy the levels of clotting factors will show the following order: VII $<$ IX $<\mathrm{X}<$ II. Only when factor II, has adapted to the prevailing level of synthesis the relative levels will be equal (5). If the therapy is stopped the velocity of reappearance is again a function of halflife time and the order will be VII $>$ IX $>$ X $>$ II. Because of fluctuations in dosage and (patho)physiological circumstances, that influence the half life of the factors (metabolic status, body temperature) stable anticoagulation with all factors at the same level is less common than would be desirable. Therefore knowledge of the relative importance of the level of each individual clotting factor to the overall anticoagulant (i.e. antithrombotic) effect is of great practical importance.

For an effective anticoagulant effect the levels of the vitamin $\mathrm{K}$-dependent clotting façtors have normally to be decreased to about $20 \%$ of the normal level (6). The estimation of the potential clotting activity is usually based on an overall clotting test of the "prothrombin time" type. The relative contribution of the individual clotting factors to this "hypocoagulability" of plasma is not clearly understood. In this article we report the determination of the relative importance of each of the vitamin $\mathrm{K}$-dependent coagulation factors for the diminution of prothrombin conversion.

\section{Patients, Materials, and Methods}

\section{Patients}

46 patients with a variety of thrombotic disorders undergoing oral anticoagulation with dicoumarol drugs were selected for this study. All patients were in the optimal therapeutic range (I.S.R. 2.8-4.8) as judged by the routine thrombotest estimation in the Maastricht Thrombosis Service.

\section{Plasmas}

Blood from patients undergoing oral anticoagulant treatment was collected in trisodium citrate ( 9 volumes of blood to 1 volume of $0.13 \mathrm{M}$ trisodium citrate) and centrifugated twice for 15 minutes at $3,000 \times \mathrm{g}$ at $15^{\circ} \mathrm{C}$. Plasma samples from the 46 patients were pooled and centrifugated for 1 hour at $23,000 \times \mathrm{g}$ at $4^{\circ} \mathrm{C}$. The pooled platelet free plasma was stored at $-80^{\circ} \mathrm{C}$. Factor II, VII, IX and X deficient plasmas were obtained from Gencral Diagnostics.

\section{Thromboplastin}

Human brain thromboplastin was prepared by a modification of the method of Owren and Aas (7). The preparation obtained was 
homogenized in a Potter Elvehjem homogeniser for 3 minutes, centrifugated at $2,000 \times \mathrm{g}$ for 15 minutes and stored in $0.1 \mathrm{ml}$ aliquots at $-20^{\circ} \mathrm{C}$. Prior to use the preparation was thawed, diluted $1: 40$ with $0.05 \mathrm{M}$ Tris$\mathrm{HCl}\left(\mathrm{pH} 7.35\right.$ ) containing $0.1 \mathrm{M} \mathrm{CaCl}_{2}$ and prewarmed at $37^{\circ} \mathrm{C}$ for 1 hour. When normal plasma was incubated with this thromboplastin dilution under the same experimental conditions as used in the thrombin generation experiments the clotting time was 80 seconds.

\section{Cephaloplastin}

Cephaloplastin was obtained from Dade (Aguada, Puerto Rico, USA). The commercial reagent was diluted $1: 5$ with $0.05 \mathrm{M}$ Tris- $\mathrm{HCl}(\mathrm{pH} 7.35)$ containing $0.1 \mathrm{M} \mathrm{CaCl}_{2}$, prewarmed for 10 minutes at $37^{\circ} \mathrm{C}$ and mixed before use.

\section{Proteins}

Human prothrombin and factor $\mathrm{X}$ were prepared as described by Lindhout et al. (8). Human factor IX was prepared analogously to the method of Fujikawa et al. (9). Human factor VII was kindly supplied by Dr. C. Reutelingsperger.

\section{Commercial Reagents}

Human congenital deficient plasmas were obtained from the Behring Institute (West Germany), Soybean trypsin inhibitor (SBTI) was obtained from Sigma (St. Louis, USA). The chromogenic substrate S2238 was obtained from Kabi Vitrum (Stockholm, Sweden). All other chemicals were of the highest grade commercially available.

\section{Measurement of Clotting Factor II, VII, IX and X Activities in Dicoumarol Plasma}

The activity levels of the clotting factors II, VII, IX and $\mathrm{X}$ in dicoumarol plasma were quantitatively determined by a standard onestage method using either congenitally deficient plasma prepared as described above (factors IX and X) or commercially obtained deficient plasma (Behring Werke, FRG). The method is described in ref. 7.

\section{Measurement of Thrombin Generation in Plasma}

For the measurement of thrombin generation the procedure described by Hemker et al. (10) was used. Briefly, $240 \mu \mathrm{l}$ of plasma and $60 \mu \mathrm{l}$ of buffer (Tris- $\mathrm{HCl}, \mathrm{pH} 7.35$ ) were incubated for 4 minutes at $37^{\circ} \mathrm{C}$. Thrombin generation was triggered by the addition of $60 \mu \mathrm{l}$ of $0.1 \mathrm{M}$ $\mathrm{CaCl}_{2}$ solution containing a suitable trigger of coagulation. For activation of the extrinsic pathway the trigger consisted of thromboplastin (final dilution $1 / 240$ ) and for activation of the intrinsic pathway Cephaloplastin (final dilution 1/30) was used. At fixed time intervals, $10 \mu \mathrm{l}$ aliquots of the incubation mixture were subsampled into a test tube containing $465 \mu \mathrm{l}$ of buffer (Tris-HCl, $0.1 \mathrm{M} \mathrm{NaCl}, 0.5 \%$ albumin, $0.02 \mathrm{M} \mathrm{EDTA,} \mathrm{pH} 7.9$ ) and $25 \mu \mathrm{l}$ of $\mathrm{S} 2238(4 \mathrm{mM})$ at $37^{\circ} \mathrm{C}$. These tubes were incubated for 2 minutes at $37^{\circ} \mathrm{C}$, and then the reaction was stopped by the addition of $300 \mu \mathrm{l}$ of concentrated acetic acid. The pipettes used for sampling and stopping the reaction were connected to an Apple IIe computer, programmed to record the moment of sampling and the moment of stopping the reaction. The optical density was read at $405 \mathrm{~nm}$ in a spectrophotometer (LKBUltraspec.). From the change in optical density and the time interval between sampling and stopping the O.D./min was automatically calculated.

Measurement of the Decay Constant of Endogenous Thrombin and the Course of Prothrombinase Activity

Briefly, $120 \mu \mathrm{l}$ of plasma and $24 \mu \mathrm{l}$ of buffer (Tris-HCl, $\mathrm{pH}$ 7.35) were incubated for 4 minutes at $37^{\circ} \mathrm{C}$. Thrombin generation was triggered by the addition of $30 \mu \mathrm{l}$ of thromboplastin. Two minutes after maximal thrombin formation, $6 \mu \mathrm{l}$ of Soybean Trypsin Inhibitor (SBTI, $10 \mathrm{mg} / \mathrm{ml}$ ) were added to the incubation mixturc. As quickly as possible after the addition of SBTI, $10 \mu \mathrm{l}$ aliquots of the incubation mixture were subsampled into a test tube containing $\$ 2238(4 \mathrm{mM})$ and EDTA $(20 \mathrm{mM})$ by using the time recording pipette. The measuring procedure was the same as that described for the measurement of thrombin generation (9).

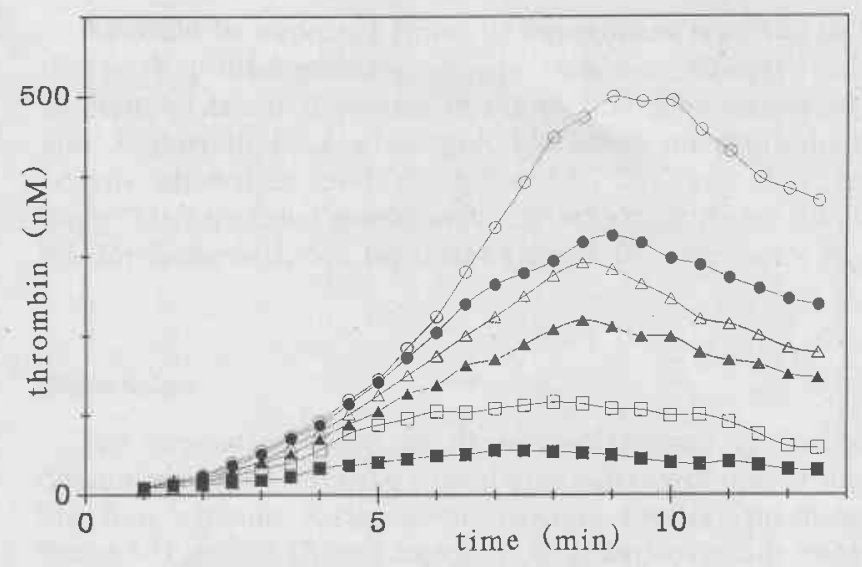

Fig. 1 Effect on thrombin generation of the addition of various amounts of factor II to dicoumarol plasma. Coagulation was triggered with thromboplastin (final dilution $1 / 240$ ). $0: 4 \mu \mathrm{M} ; 2.75 \mu \mathrm{M} ; \triangle: 1.5 \mu \mathrm{M}$; А: $1 \mu \mathrm{M} ; \square: 0.66 \mu \mathrm{M} ; \square: 0.33 \mu \mathrm{M}$

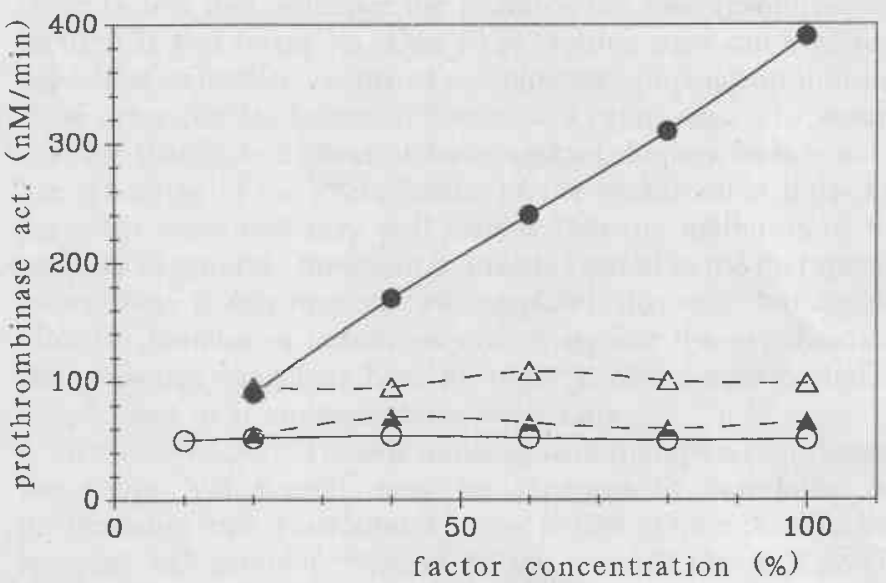

Fig. 2 Effect on prothrombinase of the addition of various amounts of factor II, VII, IX and X to dicoumarol plasma. Coagulation was triggered with thromboplastin (final dilution 1/240). (Factors VII and X) or with Cephaloplastin (final dilution 1/30). (Factor IX) The points represent the maximal prothrombinase activity calculated from the thrombin generation curves. : factor II; $\mathrm{O}$ : factor VII; $\boldsymbol{\Delta}$ : factor IX; $\Delta$ : factor $\mathrm{X}$

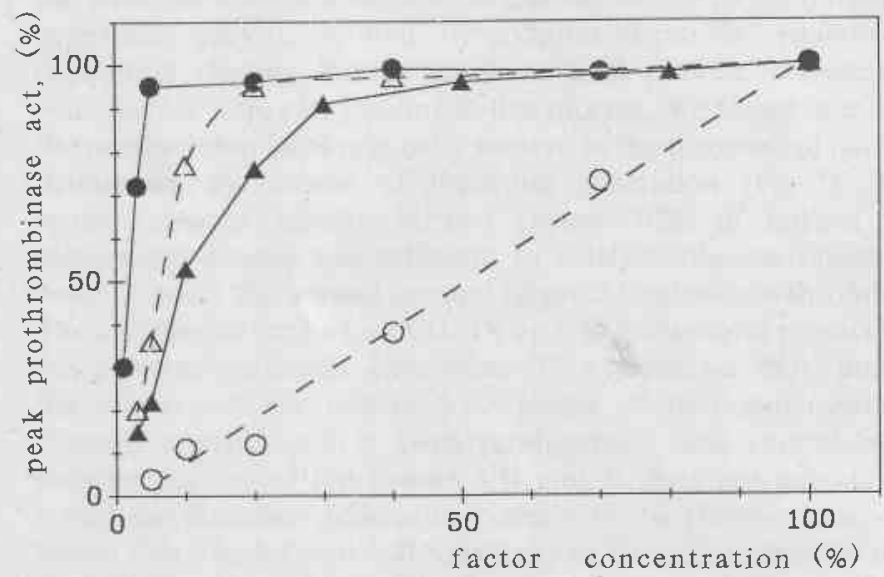

Fig. 3 Effect on prothrombinase of the addition of various amounts of factor VII, IX and X to congenital deficient plasma. Coagulation was triggered with thromboplastin (final dilution 1/240). (Factors VII and X) or with Cephaloplastin (final dilution 1/30). (Factor IX) The points represent the maximal prothrombinase activity calculated from the thrombin generation curves. $\mathrm{O}$ : factor II; - factor VII; $\triangle$ : factor IX; A: factor $\mathrm{X}$ 
The data obtained from thrombin amidolytic activity at the different time points $\left(C_{t}\right)$ were fitted to the formula $C_{t}=C_{R}+C_{o} e^{-\left(k_{1}+k_{2}\right) t}$ which gives the level at the moment of SBTI addition $\left(C_{o}+C_{R}\right)$, the steady end level $\left(C_{R}\right)$ and the decay constant $(k)$. The parameters were determined by means of an ordinary least squares fit of the model to the data. The parameter values that minimize the sum of squared residuals were calculated using the Box-Kanemasu modification of Gauss' method. The linear equations were solved by means of Haussholder transformations. The decay constant thus obtained is the sum of the $\alpha_{2}$-macroglobulin dependent decay constant $\left(\mathrm{k}_{2}\right)$ and the antithrombin III dependent decay constant $\left(k_{1}\right)$. The ratio of $k_{1}$ to $k_{2}$ was obtained from the ratio of antithrombin III bound thrombin to $\alpha_{2}$-macroglobulin bound thrombin.

The time course of prothrombinase activity $\left(\mathrm{nM} \mathrm{min}{ }^{-1}\right)$ was calculated by computer, using the thrombin generation curve and the experimentally determined decay constants of endogenous thrombin. For full technical details see ref. 10 .

\section{Results}

\section{Time Course of Thrombin Generation and Prothrombinase Formation in Normal and Dicoumarol Plasmas}

The levels of factor II, factor VII, factor IX and factor X activity in the pooled dicoumarol plasma were $22 \%, 10 \%, 40 \%$ and $19 \%$ respectively (i.e. approximatively $330,1,30$ and $33 \mathrm{nM}$ ). The decay constants $\mathrm{k}_{1}$ and $\mathrm{k}_{2}$ were estimated as $0.938 \pm$ 0.017 and as $0.232 \pm 0.004 \mathrm{~min}^{-1}$ resp. $(\mathrm{n}=25)$. Thrombin generation and prothrombinase formation in the dicoumarol plasma after triggering coagulation with thromboplastin as well as after triggering coagulation with Cephaloplastin were decreased to a similar degree $(\sim 20 \%$, results not shown).

To determine which of the vitamin K-dependent coagulation factors is responsible for the decreases of thrombin generation and prothrombinase activity, we investigated the effect of the addition of increasing amounts of respectively factor II, factor VII, factor IX or factor X to dicoumarol plasma. For studying the effects of factor II, factor VII and factor X, coagulation was triggered with thromboplastin and for studying the effect of factor IX coagulation was triggered with Cephaloplastin.

Fig. 1 shows the effect on thrombin generation of the addition of increasing amounts of factor II to dicoumarol plasma. From these and similar curves the course of prothrombinase activity was calculated. From Fig. 2 it is seen that peak prothrombinase activity increases directly proportional to the concentration of factor II added to the plasma. Theoretically we should expect a saturation phenomenon at high factor II levels. Even $4 \mu \mathrm{M}$ of factor II, more than a twice the physiological concentration showed a prothrombinase activity of $740 \mathrm{nM} / \mathrm{min}$ indicating that even this amount is still far from the saturating concentration.

Fig. 2 also shows the effects on peak prothrombinase activity of the addition of factor VII, factor IX and factor X to dicoumarol plasma. Neither the thrombin generation (not shown) nor the prothrombinase formation could be stimulated by the addition of these factors. Evidently the amount present in the dicoumarol plasma is sufficient to form the necessary prothrombinase.

\section{Effects on Prothrombinase Formation of the Addition of Factor II, Factor VII, Factor IX and Factor $X$ to Congenital Deficient Plasmas}

In order to assess the levels below which the factors VII, IX and $\mathrm{X}$ start to have an influence on prothrombin conversion, we performed further experiments in which the.effect of the addition of a various amounts of the four vitamin $\mathrm{K}$-dependent clotting factors to congenital deficient plasmas was studied. The results of these experiments are summarized in Fig. 3.
As could be expected from the experiment reported in Fig. 2 the peak prothrombinase activity increases linearly with the amounts of factor II present in the plasma. The factors VII, IX and $\mathrm{X}$ start to have a recognisable effect on prothrombinase activity when their levels fall below $5 \%, 20 \%$ and $30 \%$, respectively. Half maximal prothrombinase activity is found roughly at $8 \%$ for factor VII, $5 \%$ for factor IX and $10 \%$ for factor X.

\section{Discussion}

The hypocoagulability of dicoumarol plasma is due to the diminution of the effective coagulation activity of one or more of the four vitamin K-dependent clotting factors: prothrombin, factor VII, factor IX and factor X. Oral anticoagulant therapy is usually monitored by prothrombin time type tests. Therapeutic levels are defined by the extent to which the prothrombin time is prolonged, normalized to the international normalized ratio (I.N.R.) according to an international convention (11). Oral anticoagulant therapy influences the effective concentration of three factors that influence the prothrombin time (prothrombin, factor VII and factor X). One fixed clotting time can therefore represent an infinite varicty of combinations of concentrations of these three clotting factors. There is no a priori reason to assume that the therapeutic effect of anticoagulant therapy finds true-tolife rendering in the prolongation of the prothrombin time. On the other hand one may well assume that the inhibition of the capacity to generate thrombin is directly related to the therapeutic effect. Were it only because two completely dissimilar but equally effective families of antithrombotic drugs like the heparins and the coumarin congeners have no other known common characteristic then their antithrombin activity only.

In the initial period of oral anticoagulant therapy a reduction of the factor VII activity may be expected to determine the prothrombin time while after a longer period of time the effective response will probably depend on the reduced factor $\mathrm{X}$ and/or prothrombin activity. The exact mechanism of the development of the antithrombotic effect by diminution of clotting factors is unknown. Clinical experience has empirically teached us to keep the plasma thromboplastin time at a certain level in order to provide protection against thrombosis with a minimal risk of hemorrhagic complications (11).

In an attempt to better understand the relative contribution of the different vitamin $\mathrm{K}$-dependent clotting factors to the thrombin generating activity, we first, by addition of purified vitamin Kdependent clotting factors to dicoumarol plasma, determined what factors were rate limiting in this process. We found that only the prothrombin level originally present in the dicoumarol plasma determines the course of thrombin generation (Fig. 2). The prothrombinase activity formed (about $20 \%$ of normal) in dicoumarol plasma was sufficient to catalyze the conversion of twice or more the normal amount of prothrombin into thrombin. The addition of the factors VII, IX or X to dicoumarol plasma did not promote thrombin generation. This implicates that, during the initial and the intermediate stages of oral anticoagulant therapy, a prolonged in vitro prothrombin time caused by a reduced activity of the factors VII and X does not adequately reflect the thrombin generation potency of the plasma. Indeed it means that a high factor VII-sensitivity or factor X sensitivity of a thromboplastin tends to obscure the physiological effect of oral anticoagulation.

Our type of approach does not take into account the effect of oral anticoagulation on proteins $\mathrm{C}$ and $\mathrm{S}$. We therefore do not claim that the measurement of prothrombin alone will under all circumstances adequately measure the in vivo effects of this treatment. They do show, however, that prothrombin is the most 
important factor among those that influence the laboratory tests used for monitoring oral anticoagulant therapy.

In order to find out below which level(s) the vitamin $\mathrm{K}$ dependent clotting factors start to have an effect on prothrombinase activity, we studied the effect of the addition of the purified vitamin $\mathrm{K}$-dependent clotting factors to congenital deficient plasmas. It was shown that the prothrombinase activity linearily increases with the concentration of prothrombin and that the factors VII, IX and X start to have an effect on the prothrombinase activity when the concentrations were lower than $5 \%, 20 \%$ and $30 \%$, respectively. A half maximal prothrombinase activity is found at about $2 \%$ (factor VII), $6 \%$ (factor IX) and $10 \%$ (factor X) (Fig.3). It can be concluded that both the optimal factor $\mathrm{X}$ converting activity (tenase) and the optimal prothrombin converting activity (prothrombinase) only require small amounts of the enzymes (factor $\mathrm{IX}_{\mathrm{a}}$ and factor $\mathrm{X}_{\mathrm{a}}$ ). Also, for triggering the thromboplastin-dependent pathway, only a small amount of factor VII is needed.

In discussing these results it must be recognized that the experiments have been carried out at concentrations of tissue factor that may be lower then the amount of factor VII available. Because the factor VII - tissue factor complex is characterized by a $1: 1$ stoichiometry this means that at higher thromboplastin concentrations factor VII might more readily become rate limiting. We might therefore limit the import of this study to the use of commercial thromboplastins such as used in the practise of anticoagulant control.

On the other hand it may be argued that this type of thromboplastin concentrations probably is relatively high compared to those encountered in physiology. We have shown that the factor VII dependent activation of factor IX starts to play a role at thromboplastin concentrations that are more then tenfold lower then those used here (12). If we admit that the antihemophilic factors are important for normal physiological thrombin generation and that these factors excert their physiological function in the factor VII - factor IX (+ VIII) - factor X pathway rather then in the classical intrinsic pathway (13) then it necessarily follows that for physiological thrombin generation the prevailing tissue factor concentrations are probably much lower than those used in our experiments. In that case the factor VII dependancy of our experiments would not be unrealistic. A precise quantitative approach of this question will be possible only with the use of highly purified or recombinant tissue factor that was not available in our laboratory.

We conclude that the principal effect of oral anticoagulant therapy on the thrombin generation potential is achieved by its influencing the effective prothrombin level. We therefore think that it may be interesting to use an assay that monitors the effective prothrombin level for the control of oral anticoagulant therapy.

\section{Acknowledgements}

We thank Dr. M. C. E. van Dam-Mieras for help in redacting the article. P. Devilée for expert technical assistance, the Maastricht Thrombosis Service (head Dr. H. L. L. Frank) for access to the patients plasma and T. Camphuisen-Engel for preparation of the manuscript.

\section{References}

1 Stenflo J, Suttie J W. Vitamin K-dependent formation of $\gamma$-carboxyglutamic acid. Ann Rev Biochem 1977; 46: 157-72.

2. Hemker H C, Veltkamp J J, Hensen A, Loeliger E A. Nature of prothrombin biosynthesis. Preprothrombinaemia in vitamin $\mathrm{K}$ deficiency. Nature $1963 ; 589-90$.

3 Reekers P P M, Lindhout M J, Kop-Klaassen B B M, Hemker H C. Demonstration of three anomalous plasma proteins induced by a vitamin K antagonist. BBA 1973; 317: 559-62.

4 van Dam-Mieras M C E, Hemker H C. Half-life time and control frequency of vitamin K-dependent coagulation factors. Theoretical considerations on the place of factor VII in the control of oral anticoagulation therapy. Haemostasis 1983; 13: 201-8,

5 Loeliger E A, van der Esch B, Mattern M J, den Brabander A S A. Behaviour of factor II, VII, IX and X during long-term treatment with coumarin. Thromb Diath Haemorrh 1963; 9: 74-89.

6 Loeliger $\mathrm{E} \mathrm{A}$. The optimal therapeutic range in oral anticoagulation: History and proposal. Thromb Haemostas 1979; 42: 1141-52.

7 van Dam-Mieras M C E, Muller A D, van Dieijen G, Hemker H C. In: Methods of Enzymatic Analysis. Enzymes 3: Peptidases, Proteinases and Their Inhibitors. Vol, V. Bergmeyer H U (ed). Verlag Chemie, Weinheim 1984; pp 352-94.

8 Lindhout $\mathrm{T}$, Govers-Riemslag $\mathrm{J}$ W P, van de Waart P, Rosing J, Hemker H C. Factor $V_{a}-$ factor $X_{a}$ interaction. Effects of phospholipid vesicles of varying composition. Biochemistry 1982; 21: 5494-502.

9 Fujikawa K, Legaz M E, Kato H, Davie E W. The mechanism of activation of bovine factor IX (Christmas factor) by bovine factor $\mathrm{XI}_{\mathrm{a}}$ (activated plasma thromboplastin antecedent). Biochemistry 1974; 13: 4508-16.

10 Hemker H C, Willems G N, Béguin S. A computer assisted method to obtain the prothrombin activation velocity in whole plasma independent of thrombin decay processes. Thromb Haemostas 1986; 56: 9-17.

11 Loeliger E A, van Dijk-Wierda C A, van den Besselaar A M H P, Broekmans A W, Roos J. Anticoagulant control and the risk of bleeding. In: Anticoagulants and Myocardial Infarction. Meade T W (ed). John Wiley, Chichester.

$12 \mathrm{Ma} \mathrm{Xi}$, Béguin $\mathrm{S}$, Hemker $\mathrm{H}$ C. The importance of factor IX dependent prothrombinase formation - The Josso Pathway - in clotting plasma. Haemostasis 1989; accepted.

13 Hemker H C. Why do hemophiliacs bleed? "In memory of François Josso". Scand J Haematol 1984; 33: 11-9.

Received January 13, 1989 Accepted after revision May 12, 1989 